Check for updates

Cite this as: $B M J 2020 ; 371: \mathrm{m} 4929$ http://dx.doi.org/10.1136/bmj.m4929 Published: 23 December 2020

\section{Apply for the 2021 BMJ Student Clegg Scholarship}

The Student BMJ Clegg Scholarship is a great opportunity to gain an insight into how a medical journal is run, get involved in creating engaging educational material, and learn how to get published.

We are looking for four students who are studying medicine within the European Union who will be able to spend two days a week with us, remotely, over an eight week period. If covid-19 permits, there will be the opportunity to spend time in The BMJ office in London, but this will be finalised nearer the time. As well as being an excellent opportunity for a summer holiday project we also welcome applicants who want to undertake this scholarship as part of their medical elective. To apply, you must be motivated and full of ideas.

As a Clegg scholar, you will spend your time researching, writing, and reviewing features and educational content to gain an insight into how publications such as The BMJ and BMJ Student are put together. You might also virtually attend and report from press conferences, perform interviews, and create multimedia content.

As this is a virtual placement, we will not be reimbursing travel or accommodation. However, we pay all Student BMJ scholars a grant of $€ 1200\left(€_{1310}\right)$. Students at any stage of their medical degree are welcome to apply, but preference will be given to those with writing or teaching experience.

\section{Views from previous Clegg scholars}

\section{Laith Alexander - 2020 Scholar}

The Clegg scholarship experience was invaluable in developing my writing and critical analysis skills. The environment was supportive and collaborative, and I worked closely with editors to publish several articles in BMJ Student. There were also opportunities to attend editorial meetings where I gained insight into the mechanics behind a world leading journal. The whole team worked cohesively despite the challenges posed by a virtual format. I would recommend the Clegg scholarship to any student with a keen interest in medical journalism.

\section{Declan Murphy-2017 scholar}

Guided by the highly supportive mentorship of the BMJ team, I spent six weeks creating and editing Student $B M J$ content. The skills I learnt from my time as a Clegg Scholar continue to benefit me, particularly in my efforts to publish academic and medical journalism articles.

To apply, please send

- A covering letter (maximum 400 words) stating why you would be suitable for the position. Please also make clear the dates between March and August 2021 that you are available, which medical school you are attending, and which year you are in

- Your CV (maximum 2 pages)

- Write one article aimed at students in the style of BMJ Opinion-see guidance here

- Outline one feature article that you would like to work on while you are on the scholarship. Please present your ideas as a bullet point plan that is as detailed as possible.

- Outline an idea for one Sharp Scratch episode. Please present your ideas as a bullet point plan that outlines at least three topics of conversation that fit your theme, and who an expert guest could be for the episode.

Please send your applications to: nnabavi@bmj.com

The closing date for applications is 5 pm on Monday 1 February 2021. We will interview shortlisted candidates by video call in February 2021. 